Olga V. MALTSEVA,

Candidate of Philology (PhD), Associate Professor of the Department of General and Slavic Linguistics; Odessa I. I. Mechnikov National University; 24/26 Frantsuzskiy blvd., Odessa, 65058, Ukraine; tel.: +38(048)7465697; e-mail: lorrizzy@gmail.com; ORCID ID: 0000-0002-3326-6812; SPIN: 8724-4410

Elena S. KOSENK0,

Master student of the Department of General and Slavic Linguistics, Odessa I. I. Mechnikov National University; 24/26 Frantsuzskiy blvd., Odessa, 65058, Ukraine; tel.: +38(048)7465697; e-mail: +38(048)7465697; e-mail: loonloon@ukr.net; ORCID ID: 0000-0002-9344-9805

\title{
THE ALPHABET “DREVLESLOVENSKAYA BUKVITSA" AS A REPRESENTANT OF FOLK LINGUISTICS
}

Summary. The purpose of the article is to prove that the alphabet "Drevleslovenskaya Bukvitsa" is a modern falsification. The object of the analysis is the alphabet "Drevleslovenskaya Bukvitsa", the subject of the research is the problem of falsifications in modern folk linguistics. The work uses historical and descriptive methods and comparative analysis. The result of the study is to draw attention to the problems of studying and disseminating non-scientific hypotheses in the field of linguistics. The material of the article can be used in the process of teaching students as a way to combat unscientific knowledge. Conclusions. The totality of non-professional linguistic concepts is usually called folk linguistics. The main directions in the field of folk linguistics are: hypotheses about the etymology and origin of words; comparison of related and unrelated languages based on apparent similarity; reading ancient undeciphered texts using modern language; creating "ancient" texts. We refer to the latter direction as "Drevleslovenskaya Bukvitsa", which, although not actually a text, is interpreted as "the authentic ancient alphabet of the Slavs". Professional scientific study of the "Drevleslovenskaya Bukvitsa" was not carried out, as any specialist can easily determine its fake. However, the main problem is that this "alphabet" is actively published and distributed among the population, which wants to know the "truth" about the antiquity of the Russian / Slavic language, which is "carefully hidden" by linguists. We carried out a comparative analysis of the "Drevleslovenskaya Bukvitsa" and the Cyrillic alphabet and came to the conclusion that the "Bukvitsa" cannot be the most ancient Slavic alphabet, since, first, it does not have any special graphic differences from the Cyrillic alphabet, and second, it uses letters that did not have phonetic correspondences with ancient Slavic phonetics.

Key words: folk linguistics, falsification, Cyrillic alphabet, "Drevleslovenskaya Bukvitsa", history of the Russian language, alphabet, graphic.

Статтю отримано 14.11.2020 p.

https://doi.org/10.18524/2307-4558.2020.34.219524

УДК [811.161.1+811.612.91]'25'282'373:347.78.034:801.81:398.21

\section{МАЛЬЦЕВА Ольга Вадимовна,}

кандидат филологических наук, доцент кафедры общего и славянского языкознания Одесского национального университета имени И. И. Мечникова; Французский бульвар, 24/26, г. Одесса, 65058, Украина;

тел.: +38(048)7465697; e-mail: lorrizzy@gmail.com; ORCID ID: 0000-0002-3326-6812; SPIN: 8724-4410

\section{ХАНГ Ван Тхи Ле,}

бакалавр кафедры общего и славянского языкознания Одесского национального университета имени

И. И. Мечникова; Французский бульвар, 24/26, г. Одесса, 65058, Украина; тел.: +38(048)7465697; e-mail: vanlehang97@gmail.com; ORCID ID 0000-0002-5207-2853

\section{ОСОБЕННОСТИ ПЕРЕВОДА РУССКИХ ДИАЛЕКТИЗМОВ НА ВЬЕТНАМСКИЙ ЯЗЫК (НА МАТЕРИАЛЕ ЛЕКСИКИ РУССКИХ НАРОДНЫХ СКАЗОК)}

Аннотация. Целью данного исследования является системный сравнительный анализ русского и вьетнамского сказочного фольклора и выработка на основе такого анализа предложений по оптимизации, унификации и систематизации методов русско-вьетнамского перевода. Объектом анализа являются диалектизмы, встречающиеся в русских народных сказках. Предмет исследования - общие и специфические характеристики русского и вьетнамского фольклорно-сказочных ономастиконов и способы передачи русских фольклорно-сказочных диалектизмов на вьетнамский язык. В работе применяется комплексная методика лингвистического анализа, включающая описательный метод, метод контекстуального и сопоставительного анализа, метод статистического анализа. В результате проведённого анализа установлено, что приёмы, используемые при переводе русских народных сказок на вьетнамский язык, весьма разнообразны. Переводчик должен знать, как гибко применять различные переводческие приёмы, чтобы, с одной стороны, не потерять первоначальный смысл сказки, а с другой - подать её, учитывая картину мира двух народов. Анализ существующей русско-вьетнамской передачи фольклорно-сказочных собственных имён выявил её неупорядоченность: у переводчиков нет единства в подходах к передаче дериватов собственных имён. Практическая значимость исследования заключается в возможности использования этих материалов в университетском курсе РКИ, как отдельный спецкурс по мастерству перевода, а также в процессе обучения специалистов-переводчиков. Данные 
выводы и рекомендации могут быть использованы в практической деятельности переводчиков русского фольклора на вьетнамский и другие иностранные языки.

Ключевые слова: русские народные сказки, русский язык как иностранный, вьетнамский язык, диалектизмы, перевод, народные традиции.

Постановка проблемы. В статье представлено исследование особенностей перевода русских народных сказок на вьетнамский язык, путём сопоставления и анализа диалектных понятий. Наше исследование помогает выявить закономерности и особенности перевода образных средств и использования их в контрастивной лингвистике. Больше всего нас интересует прагматический подход к решению проблемы.

Постановка задач исследования. Во Вьетнаме изучение русского языка широко распространено, он является обязательным иностранным языком в средних школах, а также изучается в вузах и языковых специализированных школах. Кроме того, во вьетнамском языке нет специализированного подстиля вьетнамских сказок, который есть в русском языке. Поэтому существует необходимость в определении оптимальных методов передачи фольклорно-сказочных образов, их максимально возможной унифокиации, с целью наиболее точного художественного перевода.

Диалект - (греч. dialektos - говор / наречие) - разновидность общенародного национального языка, употребляемая сравнительно ограниченным числом людей, связанных общей территорией и профессиональной деятельностью, социальной культурой и находящихся в постоянном и непосредственном языковом контакте [7].

Диалектизмы - это слова местных говоров, которые встречаются в речи выходцев из определённой диалектной среды и используются в языке художественной литературы как средство стилизации (с целью создания местного колорита, речевой характеристики персонажей) [7].

Связь с предыдущими и смежными исследованиями. Изучением диалектов и диалектизмов вьетнамские лингвисты занимаются уже давно. В 1958-1959 гг. в серии "Tiếng Địa Phương" (диалект) [12], опубликованной в журнале “Политехник», Бинь Нгуен Лок представил и объяснил южный диалект вьетнамского языка. C тех пор диалекты стали изучаться всесторонне - во всех сфорерах языка: словарный состав, семантика, грамматика, культурные и социальные функции.

Публикации русских народных сказок появились во Вьетнаме в середине 1920-х годов, после Женевского мирного договора. Они были переведены, изучены и пользовались популярностью во Вьетнаме. Углублённые исследования о том, как переводить русские сказки, стали неотъемлемой темой изучения русской и мировой народной литературы.

Изложение основного материала. Мы проводили исследование, используя сборники А. Н. Афанасьева “Народные русские сказки» [2; 3] и А. Н. Толстого “Русские народные сказки - Снегурушка и лиса» [9] для сопоставительного анализа диалектизмов в оригинальных текстах русских народных сказок и в переведённых на вьетнамский язык.

Рассмотрим основные случаи конвергенции и дивергенции сопоставляемых диалектизмов.

1. При переводе русских диалектизмов на вьетнамский язык лингвисты часто используют вьетнамские слова с аналогичными или эквивалентными значениями. Однако в некоторых случаях они игнорируют перевод диалектизма, потому что не могут найти подходящего эквивалента во вьетнамском языке. Это указывает на самобытность каждой культуры:

\begin{tabular}{|c|c|c|c|c|c|c|}
\hline \multirow{2}{*}{ H. } & \multirow{2}{*}{$\begin{array}{c}\text { Диалектизмы в оригиналь- } \\
\text { ном тексте }\end{array}$} & \multirow{2}{*}{ Значение слова } & \multirow{2}{*}{$\begin{array}{c}\text { Перевод на } \\
\text { вьетнамский язык } \\
\text { (перевод наш. - } \\
\text { Ханг) }\end{array}$} & \multicolumn{3}{|c|}{$\begin{array}{c}\text { Перевод на вьетнамский язык в зави- } \\
\text { симости от значения в литературном } \\
\text { языке } \\
\end{array}$} \\
\hline & & & & Да & $\begin{array}{l}\text { Другой } \\
\text { вариант } \\
\quad \neq\end{array}$ & $\begin{array}{c}\text { Пропущен пере- } \\
\text { вод } \\
x\end{array}$ \\
\hline 1 & $\begin{array}{l}\text { (...Пора бы за тканьё при- } \\
\text { ниматься, да таких бёрд не } \\
\text { найдут, чтобы годились на } \\
\text { Василисину пряжу....) } \\
\text { (Василиса Прекрасная) } \\
\text { [2, с. 131]. }\end{array}$ & $\begin{array}{l}\text { БЁРДо } \\
\text { ср. р. (тех., обл.) } \\
\text { Принадлежность } \\
\text { ткацкого станка, гре- } \\
\text { бень для прибивания } \\
\text { утка к ткани. }\end{array}$ & - & & & $x$ \\
\hline 2 & $\begin{array}{l}\text { “Сходи купи мне льну } \\
\text { самого лучшего, я хоть } \\
\text { прясть буду”. } \\
\text { (Василиса Прекрасная) } \\
\text { [2, с. 131]. }\end{array}$ & $\begin{array}{l}\text { ЛЁН, ЛЬНА } \\
\text { вар. ЛЬНУ (форма } \\
\text { родительного падежа) }\end{array}$ & $\begin{array}{l}\text { "Hãy mua mốt ít } \\
\text { sơi lanh, thứ tôt } \\
\text { nhât mà bà tìm } \\
\text { được nhé." }\end{array}$ & $\checkmark$ & & \\
\hline 3 & $\begin{array}{l}\text { (- Яблонь-матушка. } \\
\text { Спрячь меня!) } \\
\text { (Гуси-лебеди) } \\
{[2, \text { с. } 148] .}\end{array}$ & $\begin{array}{l}\text { ЯБЛОНЬ } \\
\text { - яблоня, ж. р. (обл.). } \\
\text { Яблоня приносит } \\
\text { яблоки. }\end{array}$ & $\begin{array}{l}\text { "H̃ỡi cây táo, mẹ } \\
\text { hiển! Hẵy che chở } \\
\text { chúng tôi!!" }\end{array}$ & $\checkmark$ & & \\
\hline 4 & $\begin{array}{l}\text { (- Нельзя ли как-нибудь } \\
\text { уйти отсюдова?») } \\
\text { (Баба-яга) } \\
{[2, \text { с. } 125] .}\end{array}$ & $\begin{array}{l}\text { отСюдОВА } \\
\text { - отсюда (наречие). }\end{array}$ & $\begin{array}{l}\text { "Không thể có } \\
\text { cách nào rời khỏi } \\
\text { đây sao?" }\end{array}$ & $\checkmark$ & & \\
\hline
\end{tabular}




\begin{tabular}{|c|c|c|c|c|c|c|}
\hline \multirow{2}{*}{$\mathrm{H}$. } & \multirow{2}{*}{$\begin{array}{c}\text { Диалектизмы в оригиналь- } \\
\text { ном тексте }\end{array}$} & \multirow{2}{*}{ Значение слова } & \multirow{2}{*}{$\begin{array}{c}\text { Перевод на } \\
\text { вьетнамский язык } \\
\text { (перевод наш. - } \\
\text { Ханг) }\end{array}$} & \multicolumn{3}{|c|}{$\begin{array}{c}\text { Перевод на вьетнамский язык в зави- } \\
\text { симости от значения в литературном } \\
\text { языке } \\
\end{array}$} \\
\hline & & & & $\underset{\checkmark a}{\text { Да }}$ & $\begin{array}{c}\underset{\text { Другой }}{\text { вариант }} \\
\neq \\
\end{array}$ & $\begin{array}{c}\text { Пропущен пере- } \\
\text { вод } \\
\text { × }\end{array}$ \\
\hline 5 & $\begin{array}{l}\text { (Ж⿱илл кузнец припеваючи, } \\
\text { никакого лиха не знал.») } \\
\text { (Лихо одноглазое) } \\
{[5, \text { с. 60]. }}\end{array}$ & $\begin{array}{l}\text { ПРИПЕВАЮЧИ } \\
\text { (наречие) жить при- } \\
\text { певаючи } \\
\text { (разг.) - жить очень } \\
\text { хорошо, в довольстве. }\end{array}$ & $\begin{array}{l}\text { "Anh thợ rèn nọ } \\
\text { sông rât sung túc, } \\
\text { phong luu." }\end{array}$ & $\checkmark$ & & \\
\hline 6 & $\begin{array}{l}\text { "Попрощалась красная } \\
\text { де́вица с парнем и даёт ему } \\
\text { ширинку узорчатую». } \\
\text { (Неосторожное слово) } \\
{[3, \text { с. } 173] .} \\
\end{array}$ & $\begin{array}{l}\text { ШИРИ́нкА } \\
\text { ширинки, ж. р. } \\
\text { Короткий отрез ткани } \\
\text { (полотна), полотенце, } \\
\text { платок (обл.). } \\
\end{array}$ & $\begin{array}{l}\text { "Cô gái đỏ nói lời } \\
\text { tạm biệt với chàng } \\
\text { trai và cho anh ta } \\
\text { một chiếc khăn." }\end{array}$ & $\checkmark$ & & \\
\hline 7 & $\begin{array}{l}\text { "Поди-ка, старуха, по ко- } \\
\text { робу поскреби, по сусеку } \\
\text { помети, не наскребёшь ли } \\
\text { муки на колобок” } \\
\text { (Колобок) [9]. }\end{array}$ & $\begin{array}{l}\text { Поди-кА } \\
\text { (разг.) как пойди, по- } \\
\text { пробуй, попытайся. } \\
{[6, \text { с.928]. }}\end{array}$ & $\begin{array}{l}\text { "Này bà, hãy làm } \\
\text { một chiếc bánh mì } \\
\text { trờn nhỏ đi. Nếu } \\
\text { chịu khó vét hêt } \\
\text { trong thùng thì } \\
\text { ta cô đủ bột đây" } \\
\text { [13]. }\end{array}$ & & & $x$ \\
\hline 8 & \begin{tabular}{|l} 
“Изжарила в масле” \\
(Колобок) [9]. \\
\end{tabular} & $\begin{array}{l}\text { ИЗЖАРИЛА - по- } \\
\text { жарила". }\end{array}$ & $\begin{array}{l}\text { "Bà cho nó vào nồi } \\
\text { nướng lên" [13]. }\end{array}$ & & $\begin{array}{c}\neq \\
\text { запекла }\end{array}$ & \\
\hline 9 & $\begin{array}{l}\text { (Да в масле пряжОн) } \\
\text { (Колобок) [9]. }\end{array}$ & $\begin{array}{l}\text { ПРЯЖЕН } \\
\text { краткая форма от } \\
\text { пряжёный (= топлё- } \\
\text { ный). } \\
\end{array}$ & $\begin{array}{l}\text { "Nướng trong lò } \\
\text { lửa đỏ" }\end{array}$ & & $\begin{array}{c}\neq \\
\text { Запечен- } \\
\text { ный в крас- } \\
\text { ном огне } \\
\end{array}$ & \\
\hline 10 & $\begin{array}{l}\text { (...Она не лягуша, а кака- } \\
\text { нибудь хи́тра) } \\
\text { (Царевна-лягушка) } \\
{[2, \text { с. } 260] .}\end{array}$ & $\begin{array}{l}\text { ХИТРА } \\
\text { чародейка. }\end{array}$ & $\begin{array}{l}\text { "Cô ấy không phải } \\
\text { là một con êch, mà } \\
\text { là một nàng tiên." }\end{array}$ & $\checkmark$ & & \\
\hline
\end{tabular}

2. Собственное имя, используемое в русских народных сказках, является типичной особенностью русского текста. При переводе собственного имени в сказках с русского на вьетнамский язык переводчики часто используют фонетический метод. Транскрипция и транслитерация предполагают введение в текст чужого слова при помощи графических средств языка, перевода соответствующих реалий с максимально допустимым данными средствами фонетическим приближением к его оригинальной фонетической форме. Мы выбрали несколько типичных примеров:

\section{- Баба-Яга}

Скоро послышался в лесу страшный шум: деревъя трещали, сухие листья хрустели; выехала из лесу баба-яга - в ступе едет, пестом погоняет, помелом след заметает [2, с. 129]. - Rồi bát ngờ cồ cảm thấy mặt đất dưới chân đang rung chuyển, và kia là Baba-Yaga đang bay đến trong một cái cồi, đung đưa cái chày của mu nhu cái roi và dọn đường bằng một cái chôi [14].

Баба Яга (рус. Я̆а, яга-баба, еги-баба, ягая, Ягишна, Ягабова, Егибоба; “ведьма), (лесная баба», (болотная ведьма») - важный персонаж в мифологии и фольклоре (особенно в волшебной сказке) славянских народов. Уродливая старуха, владеющая волшебными предметами и наделённая магической силой. В ряде сказок уподобляется ведьме, колдунье [4]. Имя Бабы-Яги состоит из двух элементов. Первый - “Баба» - в большинстве славянских языков означает "старуха» или "бабушка». Это происходит от презрительных слов, которые дети используют в современных языках [10, с. 19]. И второй элемент — (яга» — имеет сложную этимологию: (j)egga, “Jędza» (в польск.), возможно, относится к литовскому ингису ((ленивый, ленивец) или (ленивые люди»), или к древним норвежским әккал (“болезненные)), или к древним английским инкал ((спрашивай, сомневайся; спорь») [11, с. 542]. Имеется также версия, что Яга - от этнонима ядъги, одного из племён скифско-сарматского происхождения, в котором намного дольше, чем у других племён, сохранялся матриархат [1].

Во Вьетнаме нет аналога для этого персонажа. Поэтому при переводе сказок, связанных с Бабой-Ягой, переводчик уважает исходный текст и сохраняет имя правильное, то есть исходное, чтобы точнее передать этнические и культурные характеристики, а также значение персонажа: Баба Яәа - Baba-Yaga.

- Иван, Василиса, Никита и т. д.

Некоторые другие собственные имена, используемые в русских сказках, например: Иван, Василиса, Алёнушка, - сохраняются при переводе на вьетнамский язык, так как необходимо не пренебрегать оригинальным текстом и применять фонетическую транскрипцию. Подобные имена собственные подчёркивают культурную самобытность России, а читатели могут увидеть, в какой стране обычно используется эти имена. Поэтому в переводных текстах встречаются: Баба-Яга / Baba Yaga, 
Caдко/ Sadko, Сивка-Бурка (конь) / Sivka-Bourka, Hикита Кожемяка (крестьянский сын)/ Nikita Kоzhemyaka, Василиса Премудрая / Vasilisa xinh đер, Иван Царевич / Ivan Tsarevich.

Во Вьетнаме не всегда применяются фонетические методы для перевода собственных имён из иностранных сказок. Возьмём, например, французскую сказку “Cendrillon” (Золушка). В оригинальной сказке собственное имя главной героини - Cendrillon, однако транслитерация здесь не используется, как Vasilisa или Ivan, а основываясь на значении, подбирается эквивалент, так как он даёт лучшее представление о героине, чем транслитерированное имя. Поэтому при переводе имени Cendrillon на вьетнамский язык получаем: Lo Lem, Xấu Xí, то есть Золушка, девушка, которая испачкана золой.

Определённую роль в переводе личных имён имеет традиция народа, на язык которого переводится сказка. Так, в некоторых вьетнамских сказках используются собственные имена, взятые из диалектов, для обозначения региональных культурных особенностей. Например, $T i$ - из северного диалекта (Бакбо) и толкуется как (мышь), с коннотациями малости и хитрости. В то же время, оно может употребляться и в реальности, потому что, следуя старым обычаям народа Кинь, нельзя использовать красивые имена, чтобы называть новорожденных детей, а только простые, такие как Тео, $T i$ (эти имена сейчас используются редко). Это связано с традицией называть детей уродливыми именами в течение 100 дней, чтобы дьявол не смог забрать ребёнка.

Выводы. В ходе проведённого исследования мы пришли к выводу, что изучение проблемы перевода и сопоставления диалектизмов, используемых в русских и вьетнамских сказках, помогает выработать предложения по оптимизации, систематизации и унификации методов их передачи в русско-вьетнамском переводе. Перевод текста сказок, является лингвокультурным процессом: с одной стороны, он предполагает языковую деятельность, а с другой, - служит целям межкультурной коммуникации, обеспечивающей взаимопонимание участников коммуникативного акта, принадлежащих к разным национальным культурам. Наибольшую сложность для переводчика представляют личных имена сказочных персонажей. При их переводе на вьетнамский язык используются разные подходы и методы, чтобы достичь максимальной әфофективности выражения.

В условиях постоянного контактирования и взаимодействия этносов перевод является источником информации, который раскрывает своеобразие культурных ценностей, обычаев и традиций, способствует взаимопониманию. Анализ диалектов русского языка может быть ориентирован на реконструкцию процесса взаимодействия разных этнических культур.

\section{Литература}

1. А Яга - настоящая женщина, хоть и баба!... URL:https://www.liveinternet.ru/users/3395230/post202077005/ (Дата обращения: 17.09.2020).

2. Аффанасьев А. Н. Народные русские сказки : в 3 т. Т. 1. Москва : Наука, 1984. 511 с.

3. Афанасьев А. Н. Народные русские сказки : в 3 т. Т. 2. Москва : Наука, 1985. 465 с.

4. Баба-Яга. Российский гуманитарный энииклопедический словарь. Т. 1. Москва : Владос : Филологический факультет СПбГУ, 2002.

5. Лихо одноглазое. Чудесные русские сказки. Москва : Эксмо, 2019. С. 60-72.

6. Лопатин В. В. Толковый словарь современного русского языка. Москва : Эксмо, 2013. 928 с.

7. Розенталь Д. Э., Теленкова М. А. Словарь-справочник лингвистических терминов. Москва : Просвещение, 1976. $543 \mathrm{c}$.

8. Степанов Е. Н. Современное состояние южнорусских переселенческих говоров Одесской области. Идиолежт русской языковой личности как отражение лингвокультурной ситуачии в славянском погранииве : сб. докл. участников Международного научного форума. Брянск : Аверс, 2019. С. 42-49.

9. Толстой А. Н. Снегурушка и лиса. Руские народные сказки в литературной обработке А. Н. Толстого. Москва : Детская литература, 1988. С. 76-85.

10. Фасмер М. Этимологический словарь русского языка : в 4 т. Москва : Прогресс, 1964. Т. 1. 562 с.

11. Фасме М. Этимологический словарь русского языка : в 4 т. Москва : Прогресе, 1973. Т. 2. 542 с.

12. Bình Nguyên Lộc. Tiếng địa phương. Tạp chí bách khoa, 1858. Số 47. [Бинь Нгуен Лок. Диалекты. Политехнический журнал, 1858. № 47$]$.

13. Chiếc bánh tròn bé nhỏ. Báo Tây Ninh online, 2012. https://baotayninh.vn/suy-ngam-chiec-banh-tron-be-nho a36067.html/ [Колобок. Тай Нинь интернет-газета, 2012].

14. Cồ tích Nga - Nàng Vasilisa Xinh đẹp / Dich giả Jess, J. K. URL : https://www.wattpad.com/5167507c\%Е1\%BB\% 95-t\%C3\%ADch-nga-n\%C3\%A0ng-vasilisa-xinh-\%C4\%91\%E1\%BA\%B9p/page/4/. [Василиса Прекрасная / пер. с рус. Jess, J. K.].

\section{References}

1. And Yaga is a real woman, albeit a "baba"!... Available at : https://www.liveinternet.ru/users/3395230/ post202077005/ (Date of treatment: 09/17/2020).

2. Afanasyev, A. N. (1984), Folk Russian fairy tales : in 3 volumes [Narodnyye russkiye skazki $: v 3$ t.], Nauka Publishing house, Moscow, vol. 1, $511 \mathrm{p}$.

3. Afanasyev, A. N. (1985), Folk Russian fairy tales : in 3 volumes [Narodnyye russkiye skazki $: v 3 t$.]. Nauka Publishing house, Moscow, vol. 2, $465 \mathrm{p}$. 
4. "Baba Yaga" (2002), Russian humanitarian encyclopedic dictionary ["Baba-Yaga", Rossiyskiy gumanitarnyy entsiklopedicheskiy slovar'], Faculty of Philology, St. Petersburg State University. Vlados, Moscow, vol. 1.

5. "Dashing one-eyed" (2019), Miracle Russian fairy tales ["Likho odnoglazoye", Chudesnyye russkiye skazki], Eksmo, Moscow, pp. 60-72.

6. Lopatin, V. V. (2013), Explanatory dictionary of the modern Russian language [Tolkovyy slovar' sovremennogo russkogo yazyka], Eksmo, Moscow, 928 p.

7. Rosenthal, D. E., Telenkova, M. A. (1976), Dictionary-reference book of linguistic terms [Slovar'-spravochnik lingvisticheskikh terminov], Prosveshchenie Publishing house, Moscow, 543 p.

8. Stepanov, Ie. N. (2019), "Current state of south Russian dialects of Odessa region", The idiolect of the Russian language personality as a reflection of the linguocultural situation in the Slavic borderlands : collection of reports of the International Sci. forum participants ["Sovremennoye sostoyaniye yuzhnorusskikh pereselencheskikh govorov Odesskoy oblasti", Idiolekt russkoy yazykovoy lichnosti kak otrazheniye lingvokul'turnoy situatsii $v$ slavyanskom pogranich'ye : sb. dokladov uchastnikov Mezhdunarodnogo nauch. foruma], Avers, Bryansk, pp. 42-49.

9. Tolstoy, A. N. (1988), "Snegurushka and the Fox", Russian folk tales in the literary processing of A. N. Tolstoy ["Snegurushka i lisa", Russkiye narodnyye skazki v literaturnoy obrabotke A. N. Tolstogo], Detskaya literatura Publishing house, Moscow, pp. 76-85.

10. Vasmer, M. (1964), Etymological dictionary of the Russian language : in 4 volumes [Etimologicheskiy slovar' russkogo yazyka: $v 4 t$.], Progress Publishing house, Moscow, vol. 1, $562 \mathrm{p}$.

11. Vasmer M. (1973), Etymological dictionary of the Russian language: in 4 volumes [Etimologicheskiy slovar' russkogo yazyka: $v 4 t$.], Progress Publishing house, Moscow, vol. 2, $542 \mathrm{p}$.

12. Bình Nguyên Lộc (1858), "Tiếng địa phương", Tạp chí bách khoa, 1858, số 47. [Binh Nguyen Lok (1858), "Dialects", Polytechnic journal, 1858, no. 47].

13. "Chiếc bánh tròn bé nhỏ" (2012), Báo Tây Ninh online. Available at : https://baotayninh.vn/suy-ngam-chiecbanh-tron-be-nho a36067.html/ ["Kolobok" (2012), Tai Ninh : online newspaper].

14. "Cổ tích Nga - Nàng Vasilisa Xinh đẹp" / Dịch giả Jess, J. K. Available at : https://www.wattpad.com/5167507c\%E1\%BB\%95-t\%C3\%ADch-nga-n\%C3\%AOng-vasilisa-xinh-\%C4\%91\%E1\%BA\%B9p/page/4/. ["Vasilisa the Beautiful" / Translated by Jess, J. K.].

\section{МАЛЬЦЕВА Ольга Вадимівна,}

кандидат філологічних наук, доцент кафедри загального і слов'янського мовознавства Одеського національного університету імені I. I. Мечникова; Французький бульвар, 24/26, м. Одеса, 65058, Україна; тел.: +38(048)7465697; e-mail: lorrizzy@gmail.com; ORCID ID 0000-0002-3326-6812; SPIN: 8724-4410

\section{ХАНГ Ван Тхі Лє,}

бакалавр кафедри загального і слов'янського мовознавства Одеського національного університету

імені I. I. Мечникова; Французький бульвар, 24/26, м. Одеса, 65058, Україна; тел.: +38(048)7465697;

e-mail: vanlehang97@gmail.com; ORCID ID: 0000-0002-5207-2853

\section{ОСОБЛИВОСТІ ПЕРЕКЛАДУ РОСІूЙСБКИХ ДІАЛЕКТИЗМІВ НА В'GТНАМСЬКУ МОВУ (НА МАТЕРІАЛІ ЛЕКСИКИ РОСІЙСЬКИХ НАРОДНИХ КАЗОК)}

Анотація. Метою дослідження є системний порівняльний аналіз російського і в'єтнамського казкового фольклору і вироблення на основі такого аналізу пропозицій щодо оптимізації, уніфікації та систематизації методів російськов'єтнамського перекладу. Об'єктом аналізу є діалектизми, що зустрічаються в російських народних казках. Предмет дослідження - загальні та специфічні характеристики російського і в'єтнамського фольклорно-казкових ономастиконів і способи передачі російських фольклорно-казкових діалектизмів на в'єтнамську мову. У роботі застосовується комплексна методика лінгвістичного аналізу, що включає описовий метод, метод контекстуального і порівняльного аналізу, метод статистичного аналізу. У результаті проведеного розбору нами встановлено, що прийоми, використовувані у перекладі російських народних казок на в'єтнамську мову, дуже різноманітні. Перекладач повинен знати, як гнучко застосовувати різні перекладацькі прийоми, щоб, з одного боку, не втратити первісний зміст казки, а з іншого - подати її, враховуючи картину світу двох народів. Аналіз існуючої російсько-в’єтнамської передачі фольклорно-казкових власних імен виявив її невпорядкованість: у перекладачів немає єдиних підходів до передачі дериватів власних імен. Практична значимість дослідження полягає в можливості використання цих матеріалів в університетському курсі PMI, як окремий спецкурс із майстерністі перекладу, а також у процесі навчання фахівців-перекладачів. Висновки і рекомендації можуть бути використані у практичній діяльності перекладачів російського фольклору на в'єтнамський та інші іноземні мови.

Ключові слова: російські народні казки, російська мова як іноземна, в'єтнамська мова, діалектизми, переклад, народні традиції. 
Olga V. MALTSEVA,

Candidate of Philology (PhD), Associate Professor of the Department of General and Slavic Linguistics, I. I. Mechnikov Odessa National University; 24/26 Frantsuzsky blvd., Odessa, 65058, Ukraine; tel.: +38(048)7465697;

e-mail: lorrizzy@gmail.com; ORCID ID: 0000-0002-3326-6812; SPIN: 8724-4410

\section{HANG Van Thi Le,}

Student of the Department of General and Slavic Linguistics, Odessa I. I. Mechnikov National University;

24/26 Frantsuzsky blvd., Odessa, 65058, Ukraine; tel.: +38(048)7465697; e-mail: vanlehang97@gmail.com;

ORCID ID 0000-0002-5207-2853

\section{FEATURES OF THE TRANSLATION OF RUSSIAN DIALECTISMS INTO VIETNAMESE (BASED ON THE VOCABULARY OF RUSSIAN FOLK FAIRY TALES)}

Summary. The purpose of this study is a systemic comparative analysis of Russian and Vietnamese folklore and the development, based on such an analysis, of proposals for optimization, unification and systematization of methods of Russian into Vietnamese translation. The object of the analysis is the dialectisms found in Russian folk tales. The subject of the research is the general and specific characteristics of Russian and Vietnamese folklore and fairytale onomasticons and the ways of transferring Russian folklore and fairytale dialectisms into the Vietnamese language. The work uses a complex method of linguistic analysis, including a descriptive method, a method of contextual and comparative analysis, a method of statistical analysis. As a result of the analysis, we have established that the techniques used in translating Russian fairy-tales into Vietnamese are very diverse. The translator must know how to apply flexibly various translation techniques, so that, on the one hand, not to lose the original meaning of the tale, and on the other hand, to present it, taking into account the picture of the world of the two peoples. Analysis of the existing Russian into Vietnamese transmission of folklore and fairy-tale proper names revealed its disorder: translators do not have unity in their approaches to the transmission of derivatives of their own names. The practical significance of the study lies in the possibility of using these materials in the university course of RFL, as a separate special course on translation skills, as well as in the process of teaching specialist translators. These conclusions and recommendations can be used in the practical activities of translators of Russian folklore into Vietnamese and other foreign languages.

Key words: Russian folk tales, the Russian as a foreign language, the Vietnamese language, dialectisms, translation, folk traditions.

Статтю отримано 22.10.2020 p. 